\title{
De Juanjo a Millás en EI mundo
}

Ana Pilar Fontalba Espejo

Universidad de Córdoba

\section{Resumen}

En este artículo se propone un análisis crítico e interpretativo de la novela de Juan José Millás, El mundo (2010), como texto autoficcional en el que se pone de relieve el vínculo temático y formal entre autoficción y relato de infancia.

\section{Palabras clave}

- autoficción · memoria $\cdot$ infancia $\cdot$ Millás

\begin{abstract}
This paper aims to provide a critical and interpretative analysis about Juan José Millás' novel El mundo (2010) as an autofictional text, which emphasizes the formal and thematic link between autofiction and childhood narrative.
\end{abstract}

\section{Key words}

· Autofiction · Memory · Childhood · Millás 
Contar la vida es una práctica normal: pensamos la vida como relato, como una historia que cada uno de nosotros va componiendo con los otros, para los otros y también para nosotros mismos. Sin embargo, al hablar de autobiografía como discurso escrito en el que alguien cuenta su propia vida, hay que tener en cuenta, por un lado, que la redacción fija en una determinada forma ese relato y, por otro, que entre el que escribe, que lo hace siempre en presente, y la escritura, se abre una distancia que permite al autobiógrafo ver el texto y verse en él: es un discurso especular.

La narración, por tanto, no es una forma discursiva neutra: contar algo exige darle un orden, organizar los contenidos, de manera que en el momento en el que se elabora la narración se construyen la vida y la identidad. Aquí es fundamental el papel que desempeñan la memoria y, por consiguiente, el olvido: recuperar el pasado tal y como sucedió es imposible, lo único que nos queda es recorrer la memoria y recurrir a los recuerdos (propios o prestados). En este sentido, la autobiografía no es una "copia» de lo vivido, sino una versión subjetiva y parcial, una producción (no reproducción) de identidad. La frontera entre realidad y ficción se debilita.

$\mathrm{Al}$ revisar la concepción de sujeto en un eje diacrónico y su representación en la escritura, se detecta una evolución desde la consideración del sujeto como algo unitario y estable, que se manifestaba a través de un relato con un orden lineal, lógico y cronológico, hasta la autobiografía contemporánea, en los siglos XX y XXI, en la que se da forma a una concepción de sujeto y de identidad mucho más inestable: la identidad no es algo fijo, no es algo objetivo que pueda delimitarse y contarse tal cual. Así, nos encontramos con autobiografías que mediante, por ejemplo, una narración fragmentaria o combinando novela y autobiografía, crean el efecto de que la vida no es un trayecto ordenado y lógico, sino azaroso, improvisado, caótico, y lo mismo ocurre con la memoria y la identidad.

Este carácter creativo e imaginario se intensifica cuando el objeto que se intenta plasmar es la infancia. Esta es una etapa fundamental para la formación de la identidad y, por tanto, un elemento esencial dentro de la escritura del yo; sin embargo, son tan escasos y discontinuos los recuerdos que conservamos de aquella etapa que la tarea del autobiógrafo no puede ser otra que la de crear dicho período, teniendo únicamente como base los recuerdos prestados y esas escenas desordenadas de la memoria propia: fragmentos que consiguen flotar en las aguas del olvido.

Estas características son propias de la autoficción, término cuyo origen se remonta a 1977, con la publicación de la obra Fils, de Serge Doubrovsky, definida por el propio autor como "ficción de acontecimientos estrictamente reales» ${ }^{1}$. Este nuevo concepto llenaba la casilla que quedaba vacía en el cuadro propuesto por Lejeune sobre los géneros narrativos, en el que la columna «nombre del personaje = nombre del autor» coincidía con la fila de "pacto novelesco» (Lejeune, 1994: 67). A esta primera definición le sucedieron otras que, al ser cada vez más generales, llevaron a considerar la autoficción como una especie de cajón de sastre para acoger relatos que se resisten a cualquier intento de clasificación y que se han multiplicado en la modernidad. Por ello, Manuel Alberca (2007), tomando como base la definición de Lecarme $^{2}$, delimita las fronteras de esta confusa noción: es un género que comparte rasgos con la autobiografía y con la novela, pero que no pertenece a ninguno de ellos. Así, en palabras del autor: 
En principio, la autoficción pareciera someterse al compromiso autobiográfico al que le obliga la identidad nominal, pero al acogerse a la rúbrica «novela» dispondría de una amplia libertad fabuladora. (Alberca, 2007: 239)

Además, hace hincapié en que esta identidad nominal, elemento esencial para la autoficción, es algo que el escritor elige conscientemente; por tanto, las posibles coincidencias entre autor y protagonista no son casuales: hay una identidad entre autor-narrador-personaje que comprometería al autor a contar lo realmente vivido por él, como ocurre en la autobiografía; sin embargo, en el caso de la autoficción, este compromiso queda anulado al entrar en juego el componente ficticio, la designación de «novela». En definitiva, este género se basa, siguiendo la denominación de Alberca, en un pacto ambiguo que mezcla, por un lado, la identidad (nominal) entre autor y protagonista propia del pacto autobiográfico y, por otro lado, la libertad creativa que otorga el pacto ficcional.

Además, conviene también deslindar este género de otros tipos de novelas del $\mathrm{yo}^{3}$, cuya naturaleza es también un tanto ambigua y contradictoria: la novela autobiográfica (en la que no existe identidad nominal y el autor se camufla bajo un nombre ficticio) y la autobiografía ficticia (que es formalmente una autobiografía, pero no existe en ella ninguna identidad entre autor y personaje).

La autoficción, en definitiva, participa indistintamente del pacto autobiográfico y del ficcional, y, a diferencia de la novela autobiográfica y de la autobiografía ficticia, cuenta con la identidad nominal y ofrece un juego continuo, una lectura ambigua: el lector es incitado a remitir lo que el narrador refiere al autor, pero, a la vez, es consciente de que está leyendo un texto ficcional; la contradicción se produce al denominar «novela» a un texto aparentemente autobiográfico. Esta es la poética que se desarrolla en la novela de Juan José Millás.

Generalmente, las novelas de este autor suelen estar basadas en ambientes y personajes corrientes que sienten asombro ante la cotidianeidad que les rodea, hasta el punto de llegar a sentirse extraños, ajenos a esa realidad, lo que les lleva a buscar, voluntaria o involuntariamente, otras formas de interpretar lo que ven o lo que sucede, de manera que llegan a verse en situaciones extraordinarias que a veces rozan lo fantástico. Por tanto, son frecuentes las recurrencias a las distintas dimensiones de la realidad, al desvanecimiento de la frontera entre lo vivido y lo sońado, la vida y la muerte, lo animado y lo inanimado, lo abierto y lo cerrado, lo claro y lo oscuro, la derecha y la izquierda... Todo ello unido siempre a la reflexión metalingüística.

El mundo, pues, encaja perfectamente en la línea de todas las demás; de hecho, así es considerada por el propio autor en la contraportada y dentro del libro:

Hay libros que forman parte de un plan y libros que, al modo del automóvil que se salta un semáforo, se cruzan violentamente en tu existencia. Éste es de los que se saltan el semáforo. Me habían encargado un reportaje sobre mí mismo, de modo que comencé a seguirme para estudiar mis hábitos (...) Comprendí que la escritura, como el bisturí de mi padre, cicatrizaba las heridas al instante de abrirlas e intuí por qué era escritor. No fui capaz de hacer el reportaje: acababa de ser arrollado por una novela. (Millás, 2010: contraportada)

Sin embargo, aunque el libro se califique como novela y pueda ser leído como tal, hay en él una serie de datos y referencias que nos llevan a establecer una estrecha relación autobiográfica entre el narrador y protagonista y el autor. 
Para empezar, el narrador responde al nombre de «Juanjo» o, al final del libro, a «Millás», lo que nos confirma la identidad nominal con el autor. Por otro lado, cuenta en el libro anécdotas, experiencias, que confiesa haber atribuido a algunos personajes de sus novelas, publicadas por Juan José Millás; así, habla de La soledad era esto (1996), El orden alfabético (1998), Dos mujeres en Praga (2002), No mires debajo de la cama (1999), El jardín vacio (1981), Cerbero son las sombras (1975), Letra muerta (1984), Papel mojado (1983)... proporcionando indicios suficientes como para que el lector identifique a este narrador-protagonista con el autor.

El juego ambiguo entre lo real y lo ficticio se acentúa si contemplamos la obra desde la perspectiva del relato de infancia. En este libro tiene especial relevancia esta etapa de la vida del protagonista: es en la infancia de Millás donde se forja la identidad del escritor que posteriormente llega a ser; además, en la novela no se relata solamente lo que el niño hacía o vivía, sino también (y sobre todo) lo que el niño pensaba o imaginaba.

\section{El hombre es el niño que fue}

Para analizar El mundo como relato de infancia, debemos abordar una serie de cuestiones fundamentales: el desdoblamiento del autor en narrador (adulto) y personaje narrado (niño), la relación entre ambos yoes y el orden (o, tal vez, desorden) que la narración de la infancia impone.

En este caso, el yo de la enunciación, el narrador, el Millás adulto, evoca el pasado, su infancia, desde el presente:

No olvidaré nunca el momento en el que se volvió hacia mí, que le observaba un poco asustado, para pronunciar aquella frase fundacional:

- Fíjate, Juanjo, cauteriza la herida en el momento mismo de producirla.

Cuando escribo a mano, sobre un cuaderno, como ahora, creo que me parezco un poco a mi padre en el acto de probar el bisturí eléctrico, pues la escritura abre y cauteriza al mismo tiempo las heridas. (Millás, 2010: 8)

A raíz de esta escena, comienza a reconstruir (o construir), esencialmente desde su traslado de Valencia a Madrid, las experiencias de Juanjo, un chico de familia pobre, débil, solitario y observador.

La obra se organiza en cuatro partes y un epílogo. En la primera, «El frío», se hace hincapié en la mudanza de Valencia a Madrid ${ }^{4}$, en la pobreza de aquella familia y en las relaciones del niño dentro del hogar. Juanjo, además, era un chico bastante enfermizo, que solía padecer anemia, físicamente débil, pero con una mente muy activa $^{5}$. De hecho, tendía a recluirse, a aislarse en la buhardilla o en el hueco de la escalera ${ }^{6}$ con el propósito de elaborar en la intimidad su propio mundo, ya que él "pertenecía a otra realidad»; y, por si fuera poco, su percepción se veía, a veces, más alterada aún por el consumo de éter (Ibíd.: 28) o a causa de la fiebre.

Así pues, el niño se sentía aislado en una familia ante la que pasaba desapercibido al ser el cuarto de nueve hermanos ${ }^{7}$. La relación con los padres era un tanto ambivalente y compleja: por un lado, la sensación de rechazo con respecto al padre: «Hay ocasiones en las que papá es sólo papá y ocasiones en las que es sólo 
un hombre» (17); por otro lado, la sensación ambigua de bálsamo y amenaza de la madre eterna ${ }^{8}$.

En la segunda parte del libro, «La calle», la narración comienza a girar en torno a la vida de Juanjo fuera del hogar, donde surgirá la amistad con el Vitaminas, sus primeros deseos sexuales (Luz, una chica que pasa por la calle, y María José, la hermana del Vitaminas) y el primer contacto cercano con la muerte (pérdida del Vitaminas). Gracias a este chico, Juanjo descubre «La calle», es decir, una forma hiperreal de ver su propia calle. Los niños la observan desde un tragaluz del sótano de los padres del Vitaminas, y, al parecer, desde allí, esta adquiere unas propiedades especiales:

El Vitaminas me señaló una caja de madera a la que nos subimos para asomarnos a la calle a través de aquel ventanuco.

- Mira - dijo.

Miré y vi una perspectiva lineal de mi calle, pues en la zona donde se encontraba la tienda la acera se ensanchaba, de forma que el edificio formaba un extraño recodo. Me pareció una tontería, al menos durante los primeros minutos, pasados los cuales tuve una auténtica visión. Era mi calle, sí, pero observada desde aquel lugar y a ras del suelo poseía cualidades hiperreales, o subreales, quizá oníricas. Entonces no disponía de estas palabras para calificar aquella particularidad, pero sentí que me encontraba en el interior de un sueño en el que podía apreciar con increíble nitidez cada uno de los elementos que la componían, como si se tratara de una maqueta [...] Más que mi calle, era una versión mística de mi calle. ${ }^{9}$ (Ibíd.: 48, cursiva mía)

Esto constituye otro paso importante en la formación de la personalidad del niño y, en consecuencia, de la del adulto. A la madurez de ciertos aspectos cotidianos de la vida, se suma el hecho de ser capaz de percibir la realidad de una forma distinta a la del resto.

La tercera parte, titulada «Tú no eres interesante para mí», gira en torno a María José, el primer amor de Juanjo. Es ella la que, al pronunciar esa frase, lo mata simbólicamente. Además, a propósito, entre otras cosas, de esa muerte, se acentúa aún más (si cabe) en el niño el sentimiento de encontrarse en otra realidad ajena a la del resto: "Uno de los dos vivía en la dimensión equivocada» (173).

Esta infancia dura, triste y solitaria desemboca en la cuarta parte, «La academia», donde todo, para Juanjo, se vuelve aún más oscuro y, por tanto, se intensifica su deseo o necesidad de huir.

El sentimiento de distancia con respecto a «los otros», el ensimismamiento y la inmersión en la lectura, entre otros factores, conducen al niño al fracaso escolar. Por ello, entra en una academia de repetidores cuyo director (un cura) y sus secuaces maltratan a los muchachos (¿abusos sexuales?). La situación lleva al débil Juanjo a desear la enfermedad y la muerte. Sólo tuvo una vía de escape: huir a otra ciudad con la excusa de entrar en un seminario y hacerse sacerdote.

\section{Continuidad entre el niño y el adulto. De Juanjo a Millás}

Como se proponía al principio, es fundamental la relación entre los yoes del nińo narrado (protagonista) y del adulto que narra. Ambos son entes independientes que mantienen una relación 
de continuidad: el adulto narrador se explica por el niño que fue, a pesar de que el primero lo niegue en algún momento:

Es imposible que este hombre mayor que escucha a Bach mientras golpea con furia el teclado del ordenador haya salido de aquel muchacho sin futuro. Podría presumir de haberme hecho a mí mismo y todo eso, pero lo cierto es que resulta imposible entender lo que soy a partir de lo que fui. O soy irreal yo o es irreal él. (203)

El dolor del niño está presente en la rabia del adulto, que aún sufre y que, muy a su pesar en este caso, no deja atrás su infancia (Pittarello, 2011: 252). Sin embargo, pese a esta visión desfavorable, fue entonces cuando se fraguó su peculiar forma de mirar la realidad, su identidad como escritor. Quizá, al fin y al cabo, en esta obra, no sea sólo Valencia el Paraíso Perdido. Por ejemplo, como señala Pittarello (Ibíd.: 254), el rechazo está ausente en ciertos recuerdos como cuando narra su enamoramiento de María José, zurda, y fantasea: «Si no pertenecía al mundo en que me encontraba, y eso era evidente, tenía que pertenecer a otro, y ese otro podía ser el de los zurdos» (Millás, 2010: 138).

Además, adquiere en este tiempo la base de su formación intelectual e imaginativa: es entonces cuando se inicia y entra de lleno en el mundo de los libros y la lectura, cuando se producen los primeros delirios de su mente activa, cuando aprende a ver varias realidades o desde distintas perspectivas ${ }^{10} \mathrm{y}$ cuando tiene lugar su origen como escritor al colocar aquella coma en la frase asesina «Tú no eres interesante (,) para mí» (141-142)

Por tanto, es una mirada ambivalente la del Millás adulto con respecto al niño que fue. El adulto quisiera no haber tenido la infancia que tuvo, pero también es consciente de que sin ella no habría llegado a ser quien es: «Quizá, después de todo, aquel niño frágil hubiera sido capaz de sacar adelante algo valioso, algo distinto al resto de los niños, algo que implicaba un grado de coraje que mi padre no imaginó jamás en mí» (226).

Podría hablarse, en este caso, de una mirada compasiva o indulgente de Millás hacia Juanjo. Esta actitud se apoya en los procedimientos del humor y la ironía, tan útiles para desdramatizar aquella infancia tan hostil. Esto tiene gran relevancia en la novela y en su sentido: el narrador elige construir aquella dura infancia, a veces, desde un punto de vista cómico, como distanciándose de aquella situación. Es imposible que el niño que vivía aquellos acontecimientos se viera así a sí mismo; sólo la recreación de aquella etapa permite observarlo desde esta perspectiva. Estos recursos humorísticos se manifiestan, sobre todo, al describir las divagaciones de Juanjo: la escena del billete robado, cuando da su opinión acerca del lenguaje o al relatar la relación con los padres.

\section{Tropología de la evocación narrativa de la infancia}

El relato de infancia, como decíamos, no puede obedecer a una estructura narrativa ordenada, cronológica, como sí ocurre con otros períodos vitales (Fernández Prieto, 1997: 537-538). El relato de infancia, tal y como dice el narrador de El mundo sigue un orden que «es tan arbitrario como el 
alfabético» (Millás, 2010: 204). Este tipo de narrativa tiende a construirse en torno a un desorden que no es otro que el orden asociativo de la memoria. Quizá lo más fragmentario de El mundo sean los recuerdos de Valencia ${ }^{11}$ (16-17), pero, en realidad, toda la obra se organiza temáticamente obedeciendo a mecanismos emocionales y no lógicos: a partir de ciertos tropos que podemos considerar "puntos de enlace» entre el niño y el adulto, entre el pasado y el presente de la enunciación ${ }^{12}$. Suelen ser motivos que se mueven desde una referencia mimética (realista) hacia una dimensión metafórica. La primera de esas figuras y una de las más relevantes es el frío, que además da título a la primera parte del libro. El autor habla del frío de la infancia como de una enfermedad crónica que, si se adquiere en esta temprana etapa de la vida, se convierte en algo irreversible:

Aquel frío de entonces es el mismo que hoy, pese a la calefacción, asoma algunos días del invierno y hace saltar por los aires el registro de la memoria. Si se ha tenido frío de pequeño se tendrá frío el resto de la vida. (13)

Este frío es físico: llega con el traslado de Valencia a Madrid, el paso de la playa y el sol a la casa grande pero "rota», con goteras y con las paredes desconchadas; pero la sensación se eleva al plano emocional y hasta existencial porque «la condición de la existencia era la frialdad como la de la noche es la oscuridad» (13), y llega a ser uno de los principales símbolos de aquella infancia llena de pobreza y carente de calor humano para un niño como Juanjo, que sentía no encajar en aquella realidad, en aquel mundo hostil en el que le había tocado vivir.

No menos relevante es, continuando con el título de la segunda parte del libro, la calle. Esta metáfora simboliza la capacidad de contemplar la realidad, el mundo, de otra manera, según la perspectiva; la importancia del lugar en que nos colocamos para mirar.

Juanjo reacciona con perplejidad cuando el Vitaminas le propone "ver la calle» desde su sótano: "para ver la calle no hacía falta asomarse a ninguna ventana. Vivíamos en ella» (46). Sin embargo, después del episodio anteriormente citado en el que vive aquella primera visión, el niño se vuelve adicto a mirar la Calle. Aquella experiencia marcará también un antes y un después en la vida de Juanjo $y$, por consiguiente, en la de Millás. El narrador adulto confiesa que no ha dejado de tener este tipo de visiones y que a veces ha encontrado su calle o aquella versión mística de su calle en otros lugares que ha visitado ${ }^{13}$.

Esta vez es una vivencia positiva la que el narrador conserva, pues al contemplar la Calle, el niño aprende que hay lugares desde los que el mundo se ve de forma distinta, más compleja, menos convencional. Así el adulto compara aquel tragaluz con el psicoanálisis o la escritura, también perspectivas adecuadas para apreciar la realidad con mayor distancia y poder analizarla (104-105).

Sin embargo, para Juanjo era imposible escapar de aquella Calle que era todas las calles. Otro de los puntos de conexión entre el niño y el adulto es la fuga. Ambos son personajes en huida: Juanjo trataba de salir de aquel barrio, de aquella vida, y Millás quiere huir precisamente de aquella infancia sin lograrlo (tal vez la escritura de este libro le permite aceptarlo): 
Aunque he dedicado gran parte de mi vida a escapar de aquellas calles, no estoy seguro de haberlo conseguido. A veces, en la cama, pienso en ellas como en un laberinto en cuyo interior vivo aún atrapado. Quizá ese sentimiento explica las crisis claustrofóbicas de las que soy víctima con alguna regularidad. (24)

Como ejemplo de esa claustrofobia está la anécdota en casa del editor, de la que Millás adulto se ve en la necesidad de huir y huye por la terraza (77-78). No obstante, el episodio de huida más relevante y doloroso (tanto para el niño como para el adulto que lo cuenta) se narra en la cuarta parte («La academia»). Juanjo sufría maltratos allí y era ya incapaz de reprimir su necesidad de fuga: prefiere morir antes de continuar en aquel mundo. "Aunque ha pasado tanto tiempo, continúo corriendo calle abajo para huir de la vergüenza que me producían las palizas de la academia. Escribo estas líneas a la misma hora, más o menos, de la huida» (202)

En casa del editor, durante la experiencia mística, se produce otro enlace con la infancia de Millás: alguien le ofrece un cigarrillo, un LM (81), el mismo que fumó por primera vez y con el que, dice, «se hizo un hombre», tras enterarse de la muerte del Vitaminas (77). También, en relación con ella, es el Miércoles de Ceniza posterior al suceso cuando Juanjo acude a la iglesia con su madre. La ceniza constituye otro de los motivos de recurrencia al pasado, pues el narrador enlaza este episodio con las cenizas de sus padres, que aún conserva en el armario detrás del escritorio desde el que escribe. «Recuerda, hombre, que eres polvo y que en polvo te has de convertir. Constituía un alivio saber que la vida no era más que un paréntesis. Un alivio terrorífico. Cenizas» (112).

Y en polvo se habían convertido ya sus padres; sin embargo, lejos de la tristeza de aquel niño sin ganas de vivir, la anécdota del adulto es más cómica que trágica: cuando se dispone a llevar las cenizas al mar de Valencia, es detenido en el aeropuerto y confiscados los «restos humanos» de sus padres (114-116). No menos humorístico, aunque sí más relevante, es el segundo intento y, esta vez sí lo consigue, de deshacerse de las cenizas y cumplir la voluntad de sus progenitores. Con este acto y el viaje de vuelta de Valencia a Madrid, narrado ya en el epílogo del libro, Millás concluye la obra y, según dice, otra etapa de su vida:

Creo que fue al atravesar el cauce del río seco cuando advertí que me había convertido en un hombre sin más, un mero individuo que conducía un automóvil en cuyo maletero llevaba las cenizas de sus padres [...] De súbito, me encontraba fuera de la novela, pero intentando llevar a cabo un acto (desprenderme de los restos de mis padres) que la completaría. (226) Quizá desde el momento en el que me desprendí de las cenizas, que era un modo de poner el punto final a la novela, yo había empezado a dejar de ser Millás, incluso de ser Juanjo. (232)

El narrador, al deshacerse de los restos de sus padres, se deshace también de su infancia como carga, es decir, la ha transformado en vivencia. Las cenizas como símbolo de la capacidad de resurgir y, también, de la escritura de este libro: el acto de deshacerse de las cenizas coincide con el final. ¿Quizá El mundo, la infancia de Juanjo y parte de la vida de Millás son las cenizas de las que puede resurgir y resurge un nuevo yo?

Precisamente como consecuencia de la incapacidad del adulto para elaborar ciertas vivencias del niño, Millás necesita acudir al psicoanalista. Parece ser que el motivo principal es la relación madre-hijo: cuando nació el más pequeño de los hermanos de Juanjo, su madre estuvo a punto de morir pero sobrevivió y le 
prometió a Juanjo que nunca moriría: «La promesa funcionó al principio como un bálsamo; más tarde, como amenaza» (37).

La fortaleza de la madre hace que Juanjo niño y el adulto la vean como una fuerza de la naturaleza, algo imperecedero. Así, cuando fallece, Millás comienza a enfermar $\mathrm{y}$, tras varias visitas a distintos especialistas, le recomiendan que vaya al psicoanalista, con quien descubre que su madre seguía viva: él era, ahora, su madre (40).

Este trauma, además de ser uno de los enlaces entre el niño y el adulto, también es un punto de encuentro de esta novela con otras del autor ${ }^{14}$. Hay más metáforas con las que ocurre lo mismo; por ejemplo, sucede esto con la fiebre, muy frecuente en los personajes de Millás ${ }^{15}$, que funciona como una droga, ya que produce el efecto delirante o alucinatorio que podría ser aprovechado para la escritura: «Ninguna de las drogas que probé luego, a lo largo de la vida, me proporcionó las experiencias alucinógenas de la fiebre» (65). Es, por tanto, otra manera de alterar la percepción de la realidad. Así, el narrador afirma recordar todas las ocasiones en las que ha visto el mundo a través de la fiebre y cuenta algunas de ellas (64-68). Los delirios de las fiebres infantiles de Juanjo han dado lugar a algunos fragmentos de las novelas del adulto:

Sucedió por la tarde, cuando me subía la fiebre (...) las plantas de mis pies chocaron con las plantas de otros pies idénticos a los míos, como si debajo de las sábanas hubiera otro nińo colocado en espejo respecto a mí (...) El tiempo transcurrido no ha aminorado en absoluto el sentimiento de realidad respecto a aquel suceso que atribuí al protagonista de El orden alfabético ${ }^{16}$ (66-67).

No solo la fiebre tenía efecto alucinógeno en el niño; quizás la primera experiencia con sustancias de este tipo fuera la del éter (28), que tendrá muy presente cuando, ya adulto, consume otro tipo de sustancias como el optalidón o el hachís:

Durante años fui incapaz de utilizar el bolígrafo, que es mi alicate, sino después de haber ingerido algún medicamento. Me gustaba el optalidón (...) A los diez minutos se instalaba entre la realidad y yo una suerte de nebulosa que facilitaba nuestra relación. La realidad parecía menos afilada, perdía aristas, punta, agresividad... (27-28)

Es evidente, teniendo en cuenta estos tropos, que hay una total continuidad niño-adulto. Millás, narrador, sigue siendo Juanjo, niño narrado, y reconoce en él muchas de las características que se formaron o tuvieron origen durante la etapa de la infancia. El adulto revive, a través del tabaco, de la ceniza, del frío, de las visiones místicas de la Calle, de las crisis claustrofóbicas... las vivencias que tuvieron lugar en la infancia.

\section{Notas}

${ }^{1}$ Serge Doubrovsky, Fils, París, Galilée, 1997: contracubierta, citado por Casas, 2012: 10.

${ }^{2}$ «La autoficción es en principio un dispositivo muy sencillo: sea un relato cuyo autor, narrador y protagonista comparten la misma identidad nominal y cuya denominación genérica indica que se trata de una novela». (Autofiction, un Mauvais genre?, en Doubrovsky, Lecarme y Lejeune, 1994: 277, citado por Alberca, 2004: 237) 
${ }^{3}$ Para esta clasificación y delimitación hemos seguido la propuesta por Manuel Alberca (2007: 92)

${ }^{4}$ Para el narrador es muy importante este traslado: «el viaje de la familia a Madrid marcó un antes y un después, no sólo porque después fuimos pobres como ratas, o porque antes no hiciera frío, sino porque gracias a aquel corte sé perfectamente a qué etapa corresponde cada recuerdo». (Millás, 2010: 21) Además, Valencia se eleva a la categoría de Paraíso Perdido: «Habíamos caído en una condición infernal. Valencia, desde la distancia, se convirtió entonces no sólo en un espacio luminoso, cálido y con mar, sino en el Paraíso Perdido». (Ibíd.: 23)

${ }^{5}$ Por ejemplo, en clase se dedicaba a dibujar caras y a imaginar otras vidas (Millás, 2010: 119-121). Crea una serie de historias a partir de situaciones reales, como la del niño ciego con el que se encuentra todas las mańanas cuando su madre lo llevaba al colegio: imagina que este nińo ve cuando él cierra los ojos (Ibíd.: 19-20), la de otro niño que entra en contacto con sus pies cuando está enfermo con fiebre (Ibíd.: 66). Además, tiene algunos comportamientos peculiares que forman parte del humor o la ironía con que, a veces, el narrador adulto evoca al niño; esto ocurre, por ejemplo, el día que le roba un billete a su padre y decide destruirlo: para no dejar pruebas, rompe el billete en trozos muy pequeños y se va deshaciendo de él por distintas calles (Ibíd.: 53-54).

${ }^{6}$ Fernández Romero señala como uno de los tópicos de la infancia el aislamiento del niño en algún lugar de la casa donde éste construye su propio mundo: «En ellos el niño se refugia y retrasa su incorporación al mundo de los adultos; en estos rincones de la casa el niño puede manifestarse como tal, crearse su mundo propio y vivirlo. De ahí saldrán algunos de los mejores recuerdos de la niñez: buhardillas, desvanes, balcones, ventanas, huecos de escaleras y largos pasillos aparecerán estrechamente unidos en los relatos de infancia a la propia experiencia de ser niño». (2010: 111-112)

${ }^{7}$ Se consideraba, en cierto modo, invisible, nadie se daba cuenta de lo que hacía, nadie solía echarle en falta: «Aquel verano hice cálculos acerca del tiempo que podía permanecer fuera de la circulación sin que mis padres me echaran de menos. (...) Sólo hacían dos recuentos al día: uno a la hora de la comida y otro a la de la cena» (Millás, 2010: 50). Además, lee un relato sobre un niño secuestrado de pequeño que, ya adulto, descubre que la mujer que lo había criado, en realidad, no era su madre, y se siente identificado con él y fantasea acerca de cómo habría sido su vida si hubiera sido hijo único, o si no hubiera nacido, o si hubiera tenido menos hermanos (Ibíd.179-187).

${ }^{8}$ La relación de Juanjo con sus padres se acerca al complejo de Edipo: su padre algunas veces es solo el hombre que está con su madre. Sin embargo, él mismo da la vuelta a la situación: cuando todo el mundo le dice que se parece a su madre, él ensaya caras en el espejo para dejar de parecerse: «Los resultados, creo, fueron sorprendentes. En la actualidad me parezco más a mi padre que a mi madre. (...) Mi primera novela, Cerbero son las sombras, fue calificada por un crítico solvente como un extraño experimento "antiedípico". Creo, en efecto que me convertí en 
una especie de antiedipo. Habría matado con gusto a mi madre para quedarme a vivir con mi padre...» (Millás, 2010: 32).

${ }^{9}$ Elide Pittarello apunta a propósito de este fragmento: «He aquí otra variante de la caverna platónica, con la consabida contraposición de un espacio cerrado y oscuro a un espacio abierto y luminoso. Una vez más, no hay saber sin algún desdoblamiento y déficit del ser» (2011: 243).

${ }^{10}$ Con respecto al episodio de la calle, anota Pittarello: «Para Millás, esa imagen [cuando ve la calle por primera vez desde el sótano] seguirá condensando el apego nostálgico a lo que no puede conceptualizar. Esa cárcel de la que ansiaba escaparse de nińo aparece como refugio en los momentos de desamparo de la vida adulta, como la vez que el protagonista se fue de la concurrida fiesta que había dado un editor» (2011: 253). ${ }^{11}$ «De Valencia recuerdo el sol, la playa, y algunas secuencias inconexas, como pedazos de películas rescatadas de un rollo roto» (Ibíd.: 16)

${ }^{12}$ Podemos calificar este relato como retroprogresivo, según propone Fernández Romero: «De esta manera identificamos un proceso, un movimiento en espiral en el que el autor participa desdoblado. Dicha dualidad puede describirse, en términos sartrianos, como la formada por el être-pour-soi (el yo del presente de la enunciación) y el être-en-soi (el yo del pasado). Desde ese presente se manifiesta la necesidad de "viajar" al pasado para reconstruirlo, y así traer de nuevo al presente o, mejor hacia el futuro, las supuestas riquezas de la infancia» (2007: 51). Aunque en este caso no se trate precisamente de traer al presente las riquezas de la infancia, es evidente que el texto que tratamos tiene una estructura retrospectiva, retroprogresiva, y no progresiva o lineal.

${ }^{13}$ Además, en el episodio en casa del editor, también tiene una especie de sueńo en la que la Calle, el mundo, se le revela de manera hiperreal (Ibíd.: 77-104)

${ }^{14}$ La soledad era esto comienza con la muerte de la madre de la protagonista: «Elena estaba depilándose las piernas en el cuarto de baño cuando sonó el teléfono y le comunicaron que su madre acababa de morir» (Millás, 1996: 169) A raíz de este suceso, Elena Rincón inicia un lento proceso de metamorfosis y autodescubrimiento, con ayuda de la lectura del diario de su madre, que se desarrolla a lo largo de la novela y, en un momento dado, afirma: «Ello me reduce a la condición de un fantasma, quizá el fantasma de mi madre que se resiste a abandonar del todo este mundo aferrándose a través de mí a los objetos materiales con los que más se relacionó en vida» (Ibíd.: 243-244). Además, el trauma aparece en textos no ficcionales del autor; ocurre, por ejemplo, en $E l$ sindrome de Antón, una especie de prólogo recogido en La trilogía de la soledad (El desorden de tu nombre, La soledad era esto, Volver a casa): «Entre tanto, falleció mi madre. No creo que se tratara de un suceso externo, por eso lo relaciono aquí, junto al catálogo de cuestiones imaginarias (...) La muerte de mi madre fue en muchos aspectos una ocurrencia en el sentido de que se trató de un suceso ingenioso, no diré por qué, aunque algo se entenderá si se comprueba que coincide con el momento en que publico una novela de mayor éxito que las anteriores» (Ibíd.: 13)

${ }^{15}$ Él mismo confiesa en el libro: «En cierta ocasión, alguien me señaló 
que los personajes de mis libros siempre estaban a punto de escribir o de enfermar. A veces, enfermaban en el momento de ponerse a escribir, o escribían en el momento de enfermar» (65-66).

${ }^{16}$ Así aparece en El orden alfabético: «Me encontraba, pues, recordando estas cosas, con el cuerpo boca arriba, buscando en el techo las figuras que en otro tiempo dibujaban las grietas de la pintura, cuando percibí sobre las plantas de mis pies la presión de otras plantas de dimensiones idénticas, como si hubiera otro cuerpo también echado boca arriba al otro lado de un espejo invisible (...) Entonces adiviné que aquellos pies eran también los míos, pero en la versión del otro lado» (Millás, 1998: 62)

\section{Referencias bibliográficas}

Alberca, M. (2007). El pacto ambiguo. Madrid: Biblioteca Nueva. (2004). La invención autobiográfica. En Fernández Prieto, C. y Hermosilla, M.Á. (eds.) Autobiografía en España: un balance (Pp. 235-255). Madrid: Visor Libros.

Andres-Suárez, I. y Casas, A. (eds.) (2009). Juan José Millás. Grand Sèminaire de Neuchâtel. Coloquio Internacional Juan José Millás. Madrid: Arco-Libros.

Bértolo Cadenas, C. (1983). Apéndice. En Millás, J.J. Papel mojado (Pp. 185-213). Madrid: Anaya.

Casas, A. (2012). La autoficción. Reflexiones teóricas. Madrid: Arco-Libros. Coetzee, J. (2004). Infancia. Barcelona: Debolsillo.

Fernández Cubas, C. (2011). Cosas que ya no existen. Barcelona: Tusquets. Fernández Prieto, C. y Hermosilla, M.A. (eds.) (2004). Autobiografía en España: un balance. Madrid: Visor Libros.

Fernández Prieto, C. (1997). El paisaje de infancia en la autobiografía. En Hermosilla, M.A. et all. (eds.). Visiones del paisaje (Pp. 535-544). Córdoba: Universidad de Córdoba.

- (2004). De qué hablamos cuando hablamos de autobiografía. Quimera (240) 18-21.

FERNÁNDEz Romero, R. (2007). El relato de infancia y juventud en España (1891-1942). Granada: Editorial Universidad de Granada.

Lejeune, PH. (1994). El pacto autobiográfico y otros estudios. Madrid: Megazul. Millás, J.J. (2010) El mundo. Barcelona: Planeta.

(1996). Trilogía de la soledad: El desorden de tu nombre, La soledad era esto y Volver a casa. Madrid: Alfaguara.

Pittarello, E. (2011). Las metamorfosis de Juan José Millás. En Champeau, G. et all. (eds.). Nuevos derroteros de la narrativa española actual (Pp. 239-256). Zaragoza: Prensas universitarias.

\section{Fontalba Espejo, Ana Pilar}

«De Juanjo a Millás en El mundo». El hilo de la fábula. Revista anual del Centro de Estudios Comparados (18), 79-90. 